\title{
New insights into the genetics of fibromyalgia
}

\author{
Dong-Jin Park and Shin-Seok Lee
}

Department of Rheumatology, Chonnam National University Hospital, Gwangju, Korea

Received: June 22, 2016

Accepted: September 6, 2017

\section{Correspondence to}

Shin-Seok Lee, M.D.

Department of Rheumatology, Chonnam National University Hospital, 42 Jebong-ro, Dong-gu, Gwangju 61469, Korea

Tel: +82-62-220-6591

Fax: +82-62-225-8578

E-mail: shinseok@chonnam.ac.kr
Although debate on the concept of fibromyalgia (FM) has been vigorous ever since the classification criteria were first published, FM is now better understood and has become recognized as a disorder. Recently, FM has come to be considered a major health problem, affecting $1 \%$ to $5 \%$ of the general population. As familial aggregations have been observed among some FM patients, genetic research on FM is logical. In fact, genome-wide association studies and linkage analysis, and studies on candidate genes, have uncovered associations between certain genetic factors and FM. Genetic susceptibility is now considered to influence the etiology of FM. At the same time, novel genetic techniques, such as microRNA analysis, have been used in attempts to improve our understanding of the genetic predisposition to FM. In this article, we review recent advances in, and continuing challenges to, the identification of genes contributing to the development of, and symptom severity in, FM.

Keywords: Fibromyalgia; Genes; Susceptibility; Polymorphism

\section{INTRODUCTION}

A considerable proportion of the general population suffers from pain symptoms; population-based studies have shown that $10 \%$ to $55 \%$ of the population experience diverse chronic pain symptoms at any given time [1]. Fibromyalgia (FM) is a common and complex chronic pain syndrome that affects $1 \%$ to $5 \%$ of the population [2]. FM is now defined as chronic widespread pain (CWP), persisting for more than 3 months, without any obvious organic lesion. FM is commonly accompanied by additional symptoms, such as joint stiffness, fatigue, sleep disturbance, cognitive dysfunction, and depression $[3,4]$. Although debate on the concept of FM has continued ever since the time of first publication of the classification criteria, FM is now better understood and is generally recognized as a disorder [5].

Patients with FM exhibit mental and physical disabilities and a significantly impaired quality-of-life [6]. FM imposes a major strain on healthcare resources, accompanied by high disease-related medical costs $[7,8]$. As FM is now recognized as a major health problem, many investigators have sought to explore the pathophysiology of FM. Although the etiology of FM remains unclear, significant advances have been made in our understanding of the pathophysiology of FM. The recognition of central sensitization is representative of these advances, providing an evidence-based explanation for chronic pain, including that of FM [9]. Central sensitization refers to blunting of inhibitory pain pathways and alterations in neurotransmitter levels, leading to abnormal processing of sensory signals within the central nervous systems (CNS), eventually lowering the threshold of pain and amplifying the sensations from normal signals, causing chronic pain [10].

Currently, the pathophysiology of FM is considered to involve the interaction of several factors, including abnormalities in the neurobiological and autonomic nervous systems, genetic factors, psychological variables, and environmental factors [11]. In this article, we review the current explanations for the pathophysiology of FM, focusing on genetic factors involved in the development 
of, and symptom severity in, FM.

\section{EVIDENCE FOR A GENETIC PREDISPOSITION TO FIBROMYALGIA}

\section{Genetic factors contributing to chronic pain}

Pain commonly aggregates in families, and previous studies have shown that heritability explains up to $50 \%$ of the development of chronic pain [12]. Given such work [13], a revolution in molecular genetics followed, suggesting that some forms of chronic pain have genetic explanations.

The search for pain-related genes has primarily featured large linkage or association analyses; these showed that pain-related genes affected the expression or function of proteins in a manner influencing the pain response [12]. Currently, hundreds of pain-regulated genes that are thought to be relevant to pain perception or analgesia have been identified. These include the genes encoding voltage-gated sodium-channels $\left(\mathrm{Na}_{\mathrm{v}}\right)$, GTP cyclohydrolase $1(\mathrm{GCH})$, mu-opioid receptors, and catechol-O-methyl transferase (COMT); and various genes of the dopaminergic, glutamatergic, and GABAergic pathways [14]. Furthermore, numerous candidate genes have been identified from gene expression profiling (microarray) studies [15].

\section{Familial aggregation of fibromyalgia}

As the role played by genetic factors in pain mechanisms became clearer, much research effort focused on a possible genetic predisposition to FM. Familial aggregation among FM patients provided reasonable support for an association between genetic factors and the development of FM [16]. Pellegrino et al. [17] evaluated 17 families of FM patients to assess the evidence that FM might be an inherited condition. Although the study had a relatively small sample size, it was suggested that the mode of FM inheritance was autosomal-dominant. It was found that 26 (52\%) of the enrolled parents and siblings exhibited clinical evidence of FM, and an additional 11 (22\%), without apparent symptoms of FM, exhibited abnormal muscle consistency on palpation. Similar observations in terms of familial aggregation among FM patients were also reported in two studies by Buskila et al. [18] and Buskila and Neumann [19]. In one study, among 58 offspring of 20 complete nuclear families of FM-diagnosed mothers, 16 (28\%) were found to have FM. As the exposure of offspring to environmental factors, and psychological and familial factors, did not differ between those with and without FM, it was concluded that the high-level familial occurrence of the condition might be attributable to genetic factors [18]. Buskila and Neumann [19] further studied female FM patients and their close family members, such as blood relatives (parents, siblings, and children), and non-related members (husbands). The prevalence of FM among the blood relatives of FM patients was $26 \%$, whereas that among non-related members was only 19\%. Furthermore, pain sensitivity was measured using mean tender point counts. The pain sensitivities of young male and female relatives were significantly higher than those of controls. These two studies thus suggested that certain genetic factors were associated with pain sensitivity and the high-level familial occurrence of FM. Arnold et al. [20] also evaluated the familial aggregation of FM and pain sensitivity among 533 relatives of 78 probands with FM. The presence of FM was associated both with significant aggregation and higher tender point counts among the relatives of FM probands compared with those of rheumatoid arthritis probands. Another study by Arnold et al. [21] showed that the sibling recurrence risk for FM was 27.2\% (95\% confidence interval [CI], 22.5 to 31.9), yielding a sibling recurrence risk ratio of 13.6 (95\% CI, 10.0 to 18.5 ).

Moreover, FM patients exhibit familial aggregations of psychological features, such as depression and personality traits; such findings also support the idea that genetic factors contribute to the development of FM. Glazer et al. [22] assessed shared personality traits in FM patients and their first-degree relatives. Personality traits were evaluated (using the Tridimensional Personality Questionnaire [TPQ]) in 129 female FM patients, 27 female relatives with undiagnosed FM, and 30 female relatives without FM. FM patients and relatives with FM exhibited higher scores on the 'harm avoidance' subscale than did relatives without FM. Although it was not possible to fully differentiate between genetic and nongenetic factors, it was concluded that hereditary factors for personality traits contributed to the development of FM.

The fact that familial aggregation and shared psycho- 
logical traits are evident among patients with FM does not exclude roles for other non-genetic factors in the pathogenesis of FM. However, the findings described above do suggest that genetic factors make important contributions to the etiology of FM.

\section{GENOME-WIDE ASSOCIATION STUDIES IN FI- BROMYALGIA}

Based on the observational findings of familial studies, subsequent research was devoted to identification of relevant genetic mutations using various research tools. The identification of genetic risk factors can now be achieved using many different technologies, study designs, and analytical tools. Among these techniques, genome-wide association studies (GWAS) are a relatively new way to identify susceptibility genes involved in human disease, and the technique is attractive when it is sought to explore the genetic architecture or heritability of certain human conditions [23]. Feng et al. [24] performed whole-exome sequencing and subsequent directed mutation analysis to discover possible candidate genes for FM. The cited authors identified two nonsense mutations associated with high levels of specific cytokines. The $\mathrm{W}_{32} \mathrm{X}$ mutation in C11orf4o and the Q10oX mutation in in ZNF77 (zinc finger protein 77) correlated with high plasma MCP-1 (monocyte chemoattractant protein 1) and IP-10 (interferon $\gamma$-induced protein 10) levels, and with high plasma IL-12 (interleukin 12) levels, respectively. These findings suggested that inflammation, including deregulation of the expression of specific cytokines, might be associated with the development of FM. Docampo et al. [25] also explored the genetic susceptibility to FM via GWAS and copy number variant (CNV) analyses. Although no single-nucleotide polymorphism (SNP) (of more than $5 \times 10^{5} \mathrm{SNPs}$ assessed) attained the genome-wide significance threshold, 21 of the most highly associated SNPs were further replicated in 952 FM cases and 644 controls. Replication analysis identified two associated variants, an SNP in the MYT1L (myelin transcription factor 1 like) gene and an intronic CNV in the $\mathrm{NRXN}_{3}$ (neurexin 3) gene, suggesting a potential role for CNS dysfunction in FM.

Recently, Peters et al. [26] performed the first GWAS meta-analysis on 1,308 females with CWP, and 5,791 con- trols of European descent, and replicated the effects of the genetic variations, deriving suggestive evidence for associations in 1,480 CWP cases and 7,989 controls. The work identified a common genetic variant rs13361160 on chromosome 5P15.2, associated with CWP, located upstream of the chaperonin-containing-TCP1-complex-5 gene $\left(C C T_{5}\right)$ and downstream of FAM173B. Although this large genetic study targeted CWP, thus not specifically FM, the work identified promising genetic targets for study of the pathogenesis of FM.

\section{LINKAGE STUDY IN FIBROMYALGIA}

A genetic linkage study uses recombinant genetic technology to map genetic loci, based on the observation that genes that are physically close on a given chromosome typically remain linked during meiosis [27]. Similar to GWAS, linkage analysis can be used to identify regions of the genome that contain genes predisposing to certain diseases. Arnold et al. [21] performed the first genome-wide linkage scan for FM in a cohort of multicase families. The cited authors genotyped members of 116 families, evaluating 341 markers, and detected a signal in the chromosome 17p11.2-q11.2 region, which coincided with the map coordinates of the serotonin transporter gene (SLC6A4) and the transient receptor potential (TRP) vanilloid 2 (TRPV2) genes. Although subsequent sequencing analyses of these chromosome regions in FM cases were not performed, the work does suggest that the two genes are candidate FM genes.

\section{CANDIDATE GENE STUDIES IN FIBROMYALGIA}

The results of GWAS and linkage studies have expanded our understanding of the genetic basis of FM, and have suggested that several genetic markers may be FM susceptibility genes. At the same time, studies targeting potential candidate genes considered likely to be associated with the pathogenesis of FM have been performed by several investigators (Table 1). Although the data are not yet sufficient, these studies have advanced our knowledge of genetic susceptibility to FM. Associations between FM and certain genetic polymorphisms affecting the serotonergic, dopaminergic, and catecholaminergic 
pathways have been found via candidate gene analyses.

\section{Genes affecting serotonergic metabolism}

Recent studies found that FM was associated with disturbances in serum and cerebrospinal fluid (CSF) serotonin metabolism and neurotransmission; the levels of 5-HT and metabolites thereof were significantly lower in the serum and CSF of FM patients [28-30]. The serotonin system is regulated primarily by the 5-hydroxytryptamine receptor $2 \mathrm{~A}\left(5-\mathrm{HT}_{2} \mathrm{~A}\right)$ and the serotonin transporter (5-HTT) [31]. 5-HT2A is found widely throughout the CNS and is encoded by the HTR2A (5-hydroxytryptamine receptor $2 \mathrm{~A}$ ) gene. 5-HTT is also known as the sodium-dependent serotonin transporter and solute carrier family 6 member 4 , and is encoded by the SLC6A4 gene, suggested to be an FM candidate gene in one linkage study [21]. The 5-HTT regulates the transport of serotonin from synaptic spaces into presynaptic neurons, playing an important role in serotonergic neurotransmission [32]. Thus, genetic mutations affecting both serotonin receptors and 5-HTT have received attention as possible susceptibility genes in terms of the pathophysiology of FM.

In this context, Bondy et al. [33] evaluated the association between a silent polymorphism $\left(\mathrm{T}_{102} \mathrm{C}\right)$ in the 5-HT2A receptor gene and FM. The cited authors found a significant difference in the genotype distribution in FM patients; the $\mathrm{T} / \mathrm{T}$ genotype was decreased and both the $\mathrm{T} / \mathrm{C}$ and $\mathrm{C} / \mathrm{C}$ genotypes were increased, compared with controls. Moreover, pain symptoms were significantly higher among patients with the $\mathrm{T} / \mathrm{T}$ genotype. Mergener et al. [34] also suggested that the $\mathrm{T}_{102} \mathrm{C}$ polymorphism was a genetic susceptibility factor for FM. However, Gursoy et al. [35] found no difference in the level of the $\mathrm{T}_{102 \mathrm{C}}$ polymorphism between FM patients and controls. However, the genotype was associated with symptom severity. The $\mathrm{T} / \mathrm{T}$ genotype was associated with psychiatric symptoms and lower pain thresholds in FM patients. Tander et al. [36] reported that polymorphisms in 5-HT2A seemed not to contribute to susceptibility to FM. Nevertheless, a recent meta-analysis concluded that

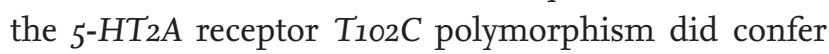
susceptibility to FM [37]. However, other serotonin receptor subunit genes, such as $H T_{3} A$ and $H T_{3} B$, were not associated with the development of FM [38].

Some investigators have also evaluated the association between the promoter region of the 5-HTT gene and the development of FM. Offenbaecher et al. [39] showed that the frequency of the $\mathrm{S} / \mathrm{S} 5$-HTT genotype was higher among FM patients than controls. Furthermore, the $\mathrm{S} / \mathrm{S}$ genotype was associated with severe symptoms of depression and other forms of psychological distress. Similarly, Cohen et al. [40] found an association between FM and a 5-HTT promoter region polymorphism. Also, the short allele of the polymorphism was associated with anxiety-related traits. However, Gursoy [41] reported that neither the polymorphism in the 5-HTT promoter region nor the variable number of tandem repeats (VNTR) variant was associated with susceptibility to FM in patients of normal psychiatric status. Moreover, no association between the 5-HTT promoter region polymorphism and FM was observed in a meta-analysis [37].

Thus, to date, any role of serotonergic gene polymorphisms in the pathophysiology of FM remains inconclusive. Nevertheless, clinical experience with $5-\mathrm{HT}_{3}$ receptor antagonists and re-uptake inhibitors used to treat FM has provided supporting evidence indicating that genes affecting the serotonergic pathway can serve as genetic markers of FM $[42,43]$. The serotonergic pathway influences diverse psychiatric symptoms, such as depression, anxiety, and fatigue, which are common in patients with FM [44]. Thus, we cannot exclude an indirect effect of such gene polymorphisms on FM. Further studies are needed to understand their significance more fully.

\section{The COMT gene}

Catechol-O-methyl transferase is a major enzyme inactivating catechol-containing drugs and catecholamine neurotransmitters such as dopamine, epinephrine, and norepinephrine. The COMT enzyme is expressed in the CNS, where it affects catecholamine neurotransmission in the prefrontal cortex [45]. Various mutations in the COMT gene induce functional enzyme impairments [46]. Thus, SNPs of the COMT gene have been suggested to contribute to FM susceptibility and symptom severity.

One mutation commonly studied in the context of FM pathophysiology is the Val158Met polymorphism (SNP rs4680). This SNP is associated with a valine (Val GTG) to methionine (Met ATG) transition at codon 158 [47]. This Met substitution reduces the activity of 
the COMT enzyme. In fact, the H/H (GG; Val-158-Val) genotype generates a fully effective enzyme, but the $\mathrm{H} / \mathrm{L}$ (AG; Met-158-Val) genotype an intermediate-activity enzyme. The L/L (AA; Met-158-Met) genotype produces a defective enzyme, which impairs the clearance of catecholamines from the CNS. A significant association between this SNP and FM development has been observed in subjects of diverse ethnic backgrounds. Matsuda et al. [48] and Barbosa et al. [49] found associations between rs4680 and FM susceptibility in a Brazilian population. Similar associations were found in a Spanish population by Vargas-Alarcon et al. [50]; in a Turkish population by Gursoy et al. [51]; and in an Israeli population by Cohen et al. [52]. Furthermore, the role of rs468o was not limited to FM susceptibility; the SNP also affected symptom severity. Barbosa et al. [49] showed that rs468o was associated with increased pain severity as measured by the Fibromyalgia Impact Questionnaire (FIQ) score. In another study, Martinez-Jauand et al. [53] found that FM patients with the Met158Met genotype exhibited higher sensitivity to painful thermal and pressure stimuli than did patients with the Val158Met genotype. Finan et al. [54] showed that COMT rs468o played a role in daily maladaptive coping and pain in FM patients. In this study, FM patients with the Met158Met genotype reported more maladaptive coping and higher-level pain than did those with the Val158Val genotype. However, others failed to find any association between this SNP and FM development. Studies in various ethnic populations revealed no association between rs4680 and FM development $[36,55]$. We evaluated the association between COMT SNPs and FM susceptibility in a Korean population, using a dataset of the Korean Nationwide FM Survey to evaluate genetic factors in, and clinical manifestations and outcomes of, FM [56]. In that largescale study, we found that rs486o was not associated with FM susceptibility. Additionally, an earlier meta-analysis revealed no association between the rs4860 SNP and FM risk [57,58]. Furthermore, in a recent meta-analysis, stratification by ethnicity failed to show any association between rs4680 and FM in European or Turkish populations [57]. Thus, evidence for an association between rs4680 and FM susceptibility remains inconclusive; further large, well-designed studies are needed.

Other COMT gene polymorphisms, including the SNPs rs6269, rs4633, and rs4818, have also been evalu- ated in FM patients $[49,50,53]$. In a Korean population, we found that $r_{s 4} \delta_{1} \delta$ and $r 4633$ may be associated with FM risk and pain sensitivity [56]. However, the roles of these SNPs in FM remain poorly understood. In addition, certain haplotypes have attracted the attention of investigators. Apart from individual SNPs, specific haplotypes of the COMT gene have been associated with pain sensitivity (individual responses to various stimuli) [59]. One particular COMT gene haplotype (ACCG), producing a defective enzyme, was associated with more sensitive perception of painful stimuli. Thus, the ACCG haplotype has been defined as a high-pain-sensitivity haplotype. Indeed, Vargas-Alarcon et al. [50] revealed associations among the ACCG haplotype, the presence of FM, and higher FIQ scores in FM patients.

Collectively, the COMT gene is the most widely investigated candidate gene in terms of FM susceptibility. Despite the variations observed among different ethnic populations, the COMT gene remains an attractive genetic target in studies of FM. To confirm the role played by the COMT gene in FM, further prospective studies are needed. The effects of various polymorphisms on the disease course and outcomes require evaluation.

\section{Genes affecting the dopaminergic pathway}

Although dopamine is well-known to play roles in the sensation of pleasure, reward-motivation behavior, and motor control, recent studies suggest that dopamine is also involved in modulating pain perception and natural analgesia [6o]. Recent work has shown that dopamine plays an important role in the descending inhibition of pain [61]. Based on this finding, researchers have shown that FM patients exhibit disrupted dopaminergic reactivity to painful stimuli $[62,63]$. Moreover, indirect evidence from a previous clinical trial also suggested a role for dopamine in the pathophysiology of FM. Pramipexole, a dopamine 3 receptor agonist, was analgesic in FM patients compared with placebo [64]. For these reasons, dopaminergic genes have been suggested as potential contributors to FM genetic susceptibility. In fact, a D4 dopamine receptor exon III repeat polymorphism has been associated with the personality profile of FM patients [65]. FM patients with this polymorphism scored poorly on the TPQ novelty-seeking personality subtest. However, to date, any role for dopaminergic genes in FM remains inconclusive. Further large-scale studies 
are needed.

\section{Candidate genes from the Korean Nationwide FM Survey}

As part of the Korean Nationwide FM Survey, we evaluated genetic factors that might be associated with FM susceptibility and symptom severity (Table 2). We performed relatively large-scale candidate gene studies, involving more than $400 \mathrm{FM}$ cases and 400 controls, to overcome the problem with the low sample sizes of previous studies. As mentioned above, we found that COMT gene polymorphisms were associated with FM risk in a Korean population, and suggested that ethnic variation in COMT gene polymorphisms might play a role in FM [56]. Moreover, based on the findings of a recent linkage study suggesting that the TRPV2 gene was a candidate FM gene [21], we investigated the association between polymorphisms in the TRPV2 and TRPV 3 genes, FM susceptibility, and symptom severity [66]. The frequencies of the alleles and genotypes of individual TRPV2 and TRPV3 genes did not differ significantly between FM cases and controls. However, we found that certain TRPV2 haplotypes may play a protective role in FM and that some genotypes and haplotypes of TRPV 3 may contribute to the symptoms of FM. Given the evidence that TRPV channels contribute to pain signaling pathways, such as peripheral and central sensitization, the TRPV gene may be a valuable target for future genetic research on FM.

Apart from the TRPV gene, Kim et al. [67] evaluated associations of GCH1 gene polymorphisms with FM. The GCH1 gene encodes an enzyme termed GTP cyclohydrolase 1 , which is the rate-limiting enzyme in the synthesis of tetrahydrobiopterin $\mathrm{BH}_{4}$ ) [68]. $\mathrm{BH}_{4}$ is an essential

Table 1. Candidate genes in the pathogenesis of FM

\begin{tabular}{|c|c|c|c|}
\hline Affected system & Genes & Effect in FM & Reference \\
\hline Serotonergic & $\begin{array}{l}\text { T102C in 5-HT2A receptor gene } \\
\text { 5-HTT promoter region (5-HTTLPR) } \\
\text { 5-HTT promoter region (5-HTTLPR) }\end{array}$ & $\begin{array}{l}\text { Development of FM and psychiatric symp- } \\
\text { toms } \\
\text { Development of FM and psychological dis- } \\
\text { tress } \\
\text { Anxiety-related traits }\end{array}$ & $\begin{array}{c}{[33,35]} \\
{[39,40]} \\
{[40]}\end{array}$ \\
\hline \multirow[t]{3}{*}{ Catecholaminergic } & Rs468o of COMT gene & $\begin{array}{l}\text { Development of FM } \\
\text { Increased pain severity } \\
\text { More maladaptive coping and pain }\end{array}$ & $\begin{array}{c}{[48,51,53]} \\
{[49,50,52]} \\
{[54]}\end{array}$ \\
\hline & ACCG haplotype of COMT gene & $\begin{array}{l}\text { Development of FM and increased pain } \\
\text { severity }\end{array}$ & {$[50,53]$} \\
\hline & Other COMT genes & Development of FM and pain sensitivity & {$[49,55]$} \\
\hline Dopaminergic & $D_{R} D_{4}$ exon3 repeat polymorphism & $\begin{array}{l}\text { Development of FM and personality profile } \\
\text { in FM patients }\end{array}$ & {$[65]$} \\
\hline \multicolumn{4}{|c|}{ 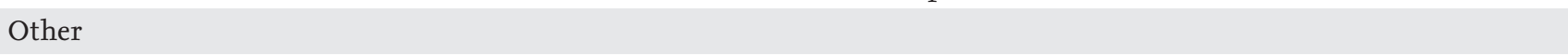 } \\
\hline Ion channels & $\begin{array}{l}\text { SCN9A gene (encoded in DRG) } \\
T R P V_{2} \text { and } T R P V_{3} \text { genes }\end{array}$ & $\begin{array}{l}\text { Development of FM and severe symptoms in } \\
\text { FM patients } \\
\text { Development of and some psychological } \\
\text { symptoms in FM patients }\end{array}$ & $\begin{array}{l}{[78]} \\
{[66]}\end{array}$ \\
\hline NO metabolism & GCHı haplotypes & Development of FM and pain sensitivity & {$[67]$} \\
\hline Adrenergic receptors & AR gene & $\begin{array}{l}\text { Development of FM and different domains } \\
\text { of FM symptoms }\end{array}$ & [79] \\
\hline Neuroplastic pathways & BDNF-NTRK2-CREB1 pathways & $\begin{array}{l}\text { Development of FM and symptoms in } \\
\text { patients }\end{array}$ & $\begin{array}{l}\text { Unpublished } \\
\text { data }\end{array}$ \\
\hline
\end{tabular}

FM, fibromyalgia; 5-HTTLPR, serotonin transporter (5-HTT) promoter region; COMT, catechol-O-methyl transferase; DRD4, dopamine-D4-receptor; DRG, dorsal root ganglia; TRPV, transient receptor potential vanilloid; NO, nitric oxide; GCHı, GTP cyclohydrolase 1; AR, adrenergic receptor; BDNF, brain-derived neurotrophic factor; NTRK2, neurotrophic tyrosine kinase receptor type 2; CREB1, cyclic adenosine monophosphate response element-binding protein 1. 
cofactor for nitric oxide (NO) production, and increased NO levels enhance pain sensitivity. Furthermore, earlier research showed that a polymorphism in the $\mathrm{GCH}_{1}$ gene was associated with reduced pain sensitivity [69]. Kim et al. [67] showed that the CCTA haplotype of the GCH1 gene was associated with protection against FM susceptibility, and significantly lowered the pain sensitivity of FM patients. Collectively, as NO metabolism is involved in various processes, including neurotransmission and immune regulation [70], these findings suggest that NO may also be involved in the altered pain perception of FM.

Using data from unpublished works, we found that polymorphisms in the brain-derived neurotrophic factor $(B D N F)$ and the adenosine monophosphate response element-binding protein (CREBI) genes were associated with susceptibility to FM. The BDNF and CREB1 genes may be candidate FM genes. BDNF is responsible for modulation of nociceptive inputs and enhances hyperalgesia via the N-methyl-D-aspartate (NMDA) receptor $[71,72]$. Binding of BDNF to its receptor (neurotrophic tyrosine kinase receptor, type 2 [NTRK2]) triggers phosphorylation of the nuclear transcription factor CREB1 [73]. The BDNF-NTRK2-CREB1 pathways have been evaluated in terms of responses to antidepressants and the pathophysiology of depression [74], which is commonly associated with FM. Thus, our results suggest that these neuroplastic pathways may afford hidden links to the development of FM.

\section{Other candidate genes}

Smith et al. [75] performed a large-scale candidate gene analysis using a dedicated gene-array chip (the Pain Research Panel), which assays variants of over 350 genes known to be involved in biological pathways relevant to nociception, inflammation, and affect. After replication analysis using an independent cohort, the authors suggested that the trace amine-associated receptor 1 (TAAR1), regulator of $\mathrm{G}$ protein signaling 4 (RGS4), cannabinoid receptor 1 (CNR1), and glutamate ionotropic receptor AMPA type subunit 4 provided (GRIA4) genes were potentially associated with the development of FM. Interestingly, previous candidate genes, including COMT SNP rs4680 and the dopamine transporter gene, were not identified in this study. Nevertheless, this research suggested potential therapeutic targets for FM.

Several ion channels have attracted attention as gates for the detection and processing of thermal, mechanical, and chemical pain stimuli [76]. For example, various sodium channelopathies have been proposed as risk factors for pathological pain conditions [77]. In FM, Vargas-Alarcon et al. [78] found that patients with polymorphisms in the sodium channel SCN9A gene, expressed in the dorsal root ganglia, had higher FIQ scores. Furthermore, Vargas-Alarcon et al. [79] found an association between adrenergic receptor $(A R)$ gene polymorphisms

Table 2. Candidate genes from the Korean Nationwide FM Survey

\begin{tabular}{|c|c|c|c|}
\hline Affected system & Gene & Effect in FM & Reference \\
\hline $\begin{array}{l}\text { Catecholaminergic } \\
\text { pathways }\end{array}$ & $\begin{array}{l}\text { Rs4S1S and rs4633 of COMT gene } \\
\text { ACG haplotype of COMT gene }\end{array}$ & $\begin{array}{l}\text { Development of FM } \\
\text { Development of FM and severe pain } \\
\text { sensitivity (measured by tender point } \\
\text { numbers) }\end{array}$ & {$[56]$} \\
\hline Ion channels & $\begin{array}{l}\text { Haplotype of } T R P V 2 \text { gene } \\
\text { SNP and haplotype of } T R P V_{3} \text { gene }\end{array}$ & $\begin{array}{l}\text { Protective role against FM } \\
\text { Fatigue symptom in FM patients }\end{array}$ & {$[66]$} \\
\hline NO metabolisms & CCTA haplotype of GCHı gene & $\begin{array}{l}\text { Protective role against FM and lower pain } \\
\text { sensitivity in FM patients }\end{array}$ & {$[67]$} \\
\hline \multirow[t]{2}{*}{ Neuroplastic pathways } & CREBr gene & $\begin{array}{l}\text { Development of FM and severe pain } \\
\text { sensitivity }\end{array}$ & Unpublished data \\
\hline & SNPs and haplotypes of BDNF gene & $\begin{array}{l}\text { Development of FM and some } \\
\text { psychological symptoms in FM patients }\end{array}$ & Unpublished data \\
\hline
\end{tabular}

FM, fibromyalgia; COMT, catechol-O-methyl transferase; TRPV, transient receptor potential vanilloid; SNP, single-nucleotide polymorphism; NO, nitric oxide; GCH1, GTP cyclohydrolase 1; CREB1, cyclic adenosine monophosphate response element-binding protein 1; BDNF, brain-derived neurotrophic factor. 
and FM. The AR gene polymorphisms were associated with a risk of developing FM and with the scores on different domains of the FIQ. Based on the roles played by AR polymorphisms in symptoms related to relentless sympathetic hyperactivity, which is frequently observed in FM patients [8o], the ARgene is also a reasonable candidate gene for FM.

\section{MICRORNA ANALYSES}

The pathophysiology and symptoms of FM are not fully explained by the genetic factors described in this review. Thus, there is still a need to evaluate other possible pain-related genes. In concert with genetic studies on FM, novel genetic techniques including microRNA analyses have been used to assess the regulation of gene expression in FM. Bjersing et al. [81] conducted the first microRNA study, identifying nine microRNAs that were significantly lower in the CSF of FM patients than controls. In another study, Bjersing et al. [82] identified eight serum-circulating microRNAs that were differentially expressed between FM patients and healthy female controls. In both microRNA studies, it was first found that certain microRNAs were associated with symptom severity in FM patients $[81,82]$. These results suggest that new genetic research tools will advance our understanding of the genetic susceptibility to FM.

\section{CONCLUSIONS}

Currently, FM is considered to result from an interaction between genetic factors and environmental factors. Earlier researchers discovered evidence for familial aggregation of FM, supporting the likelihood of a genetic background to the disease. Based on these findings, more recent research has focused on genetic features triggering alterations in gene expression in those with FM. This work has revealed that certain polymorphisms in genes involved in the serotonergic, dopaminergic, and catecholaminergic pathways may be involved in FM development. Furthermore, these polymorphisms influence not only susceptibility to FM but also symptom severity.

However, the genetic factors identified to date do not fully explain the etiology of FM. The genetic studies conducted over the past two decades have not completely explained the molecular mechanisms of FM. Moreover, the effects of genetic factors on FM disease progression, therapeutic response, and outcomes have not yet been defined. Further studies are required to evaluate the relationships between genetic polymorphisms and these clinical aspects of FM. Indeed, more prospective studies, using various genetic techniques such as GWAS, linkage analysis, candidate gene analysis, and microRNA studies, are needed to deepen our understanding of the genetic basis of FM.

\section{Conflict of interest}

No potential conflict of interest relevant to this article was reported.

\section{Acknowledgments}

We thank the patients and their families for their participation. We also thank the doctors and nurses who joined the Korean Nationwide FM Survey. This study was supported by a grant (CRI16015-1) Chonnam National University Hospital Biomedical Research Institute and by the Bio \& Medical Technology Development Program of the NRF funded by the Korean government, MSIP (2017M3A9E8O23014).

\section{REFERENCES}

1. Jakobsson U. The epidemiology of chronic pain in a general population: results of a survey in southern Sweden. Scand J Rheumatol 2010;39:421-429.

2. Jones GT, Atzeni F, Beasley M, FluB E, Sarzi-Puttini P, Macfarlane GJ. The prevalence of fibromyalgia in the general population: a comparison of the American College of Rheumatology 1990, 2010, and modified 2010 classification criteria. Arthritis Rheumatol 2015;67:568-575.

3. Choi DH, Kim HS. Quantitative analysis of nailfold capillary morphology in patients with fibromyalgia. Korean J Intern Med 2015;30:531-537.

4. Son CN, Kim SH, Chang HW, Kim JM. A neurometabolite study of chronic daily headache in patients with systemic lupus erythematosus using magnetic resonance spectroscopy: comparison with fibromyalgia patients and healthy controls. Korean J Intern Med 2016;31:1171-1177. 
5. Wolfe F, Clauw DJ, Fitzcharles MA, et al. The American College of Rheumatology preliminary diagnostic criteria for fibromyalgia and measurement of symptom severity. Arthritis Care Res (Hoboken) 2010;62:600-610.

6. Kim SK, Kim SH, Lee CK, et al. Effect of fibromyalgia syndrome on the health-related quality of life and economic burden in Korea. Rheumatology (Oxford) 2013;52:311-20.

7. Doron Y, Peleg R, Peleg A, Neumann L, Buskila D. The clinical and economic burden of fibromyalgia compared with diabetes mellitus and hypertension among Bedouin women in the Negev. Fam Pract 2004;21:415-419.

8. Spaeth M. Epidemiology, costs, and the economic burden of fibromyalgia. Arthritis Res Ther 2009;11:117.

9. Clauw DJ. Fibromyalgia: a clinical review. JAMA 2014; 311:1547-1555.

10. Staud R, Vierck CJ, Cannon RL, Mauderli AP, Price DD. Abnormal sensitization and temporal summation of second pain (wind-up) in patients with fibromyalgia syndrome. Pain 2001;91:165-175.

11. Abeles AM, Pillinger MH, Solitar BM, Abeles M. Narrative review: the pathophysiology of fibromyalgia. Ann Intern Med 2007;146:726-734.

12. Mogil JS. Pain genetics: past, present and future. Trends Genet 2012;28:258-266.

13. Hocking LJ; Generation Scotland, Morris AD, et al. Heritability of chronic pain in 2195 extended families. Eur J Pain 2012;16:1053-1063.

14. Oertel B, Lotsch J. Genetic mutations that prevent pain: implications for future pain medication. Pharmacogenomics 2008;9:179-194.

15. LaCroix-Fralish ML, Austin JS, Zheng FY, Levitin DJ, Mogil JS. Patterns of pain: meta-analysis of microarray studies of pain. Pain 2011;152:1888-1898.

16. Buskila D, Sarzi-Puttini P. Biology and therapy of fibromyalgia. Genetic aspects of fibromyalgia syndrome. Arthritis Res Ther 2006;8:218.

17. Pellegrino MJ, Waylonis GW, Sommer A. Familial occurrence of primary fibromyalgia. Arch Phys Med Rehabil 1989;70:61-63.

18. Buskila D, Neumann L, Hazanov I, Carmi R. Familial aggregation in the fibromyalgia syndrome. Semin Arthritis Rheum 1996;26:605-611.

19. Buskila D, Neumann L. Fibromyalgia syndrome (FM) and nonarticular tenderness in relatives of patients with FM. J Rheumatol 1997;24:941-944.

20. Arnold LM, Hudson JI, Hess EV, et al. Family study of fi- bromyalgia. Arthritis Rheum 2004;50:944-952.

21. Arnold LM, Fan J, Russell IJ, et al. The fibromyalgia family study: a genome-wide linkage scan study. Arthritis Rheum 2013;65:1122-1128.

22. Glazer Y, Buskila D, Cohen H, Ebstein RP, Neumann L. Differences in the personality profile of fibromyalgia patients and their relatives with and without fibromyalgia. Clin Exp Rheumatol 2010;28(6 Suppl 63):S27-S32.

23. Norrgard K. Genetic variation and disease: GWAS. Nat Educ 2008;1:87.

24. Feng J, Zhang Z, Wu X, et al. Discovery of potential new gene variants and inflammatory cytokine associations with fibromyalgia syndrome by whole exome sequencing. PLoS One 2013;8:e65033.

25. Docampo E, Escaramis G, Gratacos M, et al. Genomewide analysis of single nucleotide polymorphisms and copy number variants in fibromyalgia suggest a role for the central nervous system. Pain 2014;155:1102-1109.

26. Peters MJ, Broer L, Willemen HL, et al. Genome-wide association study meta-analysis of chronic widespread pain: evidence for involvement of the 5p15.2 region. Ann Rheum Dis 2013;72:427-436.

27. Dawn Teare M, Barrett JH. Genetic linkage studies. Lancet 2005;366:1036-1044.

28. Russell IJ, Michalek JE, Vipraio GA, Fletcher EM, Javors MA, Bowden CA. Platelet $3 \mathrm{H}$-imipramine uptake receptor density and serum serotonin levels in patients with fibromyalgia/fibrositis syndrome. J Rheumatol 1992;19:104-109.

29. Russell IJ, Vaeroy H, Javors M, Nyberg F. Cerebrospinal fluid biogenic amine metabolites in fibromyalgia/fibrositis syndrome and rheumatoid arthritis. Arthritis Rheum 1992;35:550-556.

30. Wolfe F, Russell IJ, Vipraio G, Ross K, Anderson J. Serotonin levels, pain threshold, and fibromyalgia symptoms in the general population. J Rheumatol 1997;24:555-559.

31. Eison AS, Mullins UL. Regulation of central 5-HT2A receptors: a review of in vivo studies. Behav Brain Res 1996;73:177-181.

32. Kuzelova H, Ptacek R, Macek M. The serotonin transporter gene (5-HTT) variant and psychiatric disorders: review of current literature. Neuro Endocrinol Lett 2010;31:4-10.

33. Bondy B, Spaeth M, Offenbaecher M, et al. The T102C polymorphism of the 5-HT2A-receptor gene in fibromyalgia. Neurobiol Dis 1999;6:433-439.

34. Mergener M, Becker RM, dos Santos AF, dos Santos GA, de Andrade FM. Influence of the interaction between 
environmental quality and T102C SNP in the HTR2A gene on fibromyalgia susceptibility. Rev Bras Reumatol 2011;51:594-602.

35. Gursoy S, Erdal E, Herken H, Madenci E, Alasehirli B. Association of $\mathrm{T}_{102 \mathrm{C}}$ polymorphism of the 5 - $\mathrm{HT}_{2} \mathrm{~A}$ receptor gene with psychiatric status in fibromyalgia syndrome. Rheumatol Int 2001;21:58-61.

36. Tander B, Gunes S, Boke O, et al. Polymorphisms of the serotonin-2A receptor and catechol-O-methyltransferase genes: a study on fibromyalgia susceptibility. Rheumatol Int 2008;28:685-691.

37. Lee YH, Choi SJ, Ji JD, Song GG. Candidate gene studies of fibromyalgia: a systematic review and meta-analysis. Rheumatol Int 2012;32:417-426.

38. Frank B, Niesler B, Bondy B, et al. Mutational analysis of serotonin receptor genes: HTR ${ }_{3} A$ and $H_{T} R_{3} B$ in fibromyalgia patients. Clin Rheumatol 2004;23:338-344.

39. Offenbaecher M, Bondy B, de Jonge S, et al. Possible association of fibromyalgia with a polymorphism in the serotonin transporter gene regulatory region. Arthritis Rheum 1999;42:2482-2488.

40. Cohen H, Buskila D, Neumann L, Ebstein RP. Confirmation of an association between fibromyalgia and serotonin transporter promoter region (5- HTTLPR) polymorphism, and relationship to anxiety-related personality traits. Arthritis Rheum 2002;46:845-847.

41. Gursoy S. Absence of association of the serotonin transporter gene polymorphism with the mentally healthy subset of fibromyalgia patients. Clin Rheumatol 2002;21:194-197.

42. Haus U, Varga B, Stratz T, Spath M, Muller W. Oral treatment of fibromyalgia with tropisetron given over 28 days: influence on functional and vegetative symptoms, psychometric parameters and pain. Scand J Rheumatol Suppl 2000;113:55-58.

43. Hrycaj P, Stratz T, Mennet P, Muller W. Pathogenetic aspects of responsiveness to ondansetron (5-hydroxytryptamine type 3 receptor antagonist) in patients with primary fibromyalgia syndrome: a preliminary study. J Rheumatol 1996;23:1418-1423.

44. Murphy DL, Andrews AM, Wichems CH, Li Q, Tohda M, Greenberg B. Brain serotonin neurotransmission: an overview and update with an emphasis on serotonin subsystem heterogeneity, multiple receptors, interactions with other neurotransmitter systems, and consequent implications for understanding the actions of serotoner- gic drugs. J Clin Psychiatry 1998;59 Suppl 15:4-12.

45. Matsumoto M, Weickert CS, Akil M, et al. Catechol Omethyltransferase mRNA expression in human and rat brain: evidence for a role in cortical neuronal function. Neuroscience 2003;116:127-137.

46. Zubieta JK, Heitzeg MM, Smith YR, et al. COMT val158met genotype affects mu-opioid neurotransmitter responses to a pain stressor. Science 2003;299:1240-1243.

47. Lachman HM, Papolos DF, Saito T, Yu YM, Szumlanski CL, Weinshilboum RM. Human catechol-O-methyltransferase pharmacogenetics: description of a functional polymorphism and its potential application to neuropsychiatric disorders. Pharmacogenetics 1996;6:243-250.

48. Matsuda JB, Barbosa FR, Morel LJ, et al. Serotonin receptor (5-HT 2A) and catechol-O-methyltransferase (COMT) gene polymorphisms: triggers of fibromyalgia? Rev Bras Reumatol 2010;50:141-149.

49. Barbosa FR, Matsuda JB, Mazucato M, et al. Influence of catechol-O-methyltransferase (COMT) gene polymorphisms in pain sensibility of Brazilian fibromialgia patients. Rheumatol Int 2012;32:427-430.

50. Vargas-Alarcon G, Fragoso JM, Cruz-Robles D, et al. Catechol-O-methyltransferase gene haplotypes in Mexican and Spanish patients with fibromyalgia. Arthritis Res Ther 2007;9:R110.

51. Gursoy S, Erdal E, Herken H, Madenci E, Alasehirli B, Erdal N. Significance of catechol-O-methyltransferase gene polymorphism in fibromyalgia syndrome. Rheumatol Int 2003;23:104-107.

52. Cohen H, Neumann L, Glazer Y, Ebstein RP, Buskila D. The relationship between a common catechol-Omethyltransferase (COMT) polymorphism val(158) met and fibromyalgia. Clin Exp Rheumatol 2009;27(5 Suppl 56):S51-S56.

53. Martinez-Jauand M, Sitges C, Rodriguez V, et al. Pain sensitivity in fibromyalgia is associated with catechol-Omethyltransferase (COMT) gene. Eur J Pain 2013;17:16-27.

54. Finan PH, Zautra AJ, Davis MC, Lemery-Chalfant K, Covault J, Tennen H. COMT moderates the relation of daily maladaptive coping and pain in fibromyalgia. Pain 2011;152:300-307.

55. Potvin S, Larouche A, Normand E, et al. DRD3 Ser9Gly polymorphism is related to thermal pain perception and modulation in chronic widespread pain patients and healthy controls. J Pain 2009;10:969-975.

56. Park DJ, Kim SH, Nah SS, et al. Association between cat- 
echol-O-methyl transferase gene polymorphisms and fibromyalgia in a Korean population: a case-control study. Eur J Pain 2016;20:1131-1139.

57. Lee YH, Kim JH, Song GG. Association between the COMT Val158Met polymorphism and fibromyalgia susceptibility and fibromyalgia impact questionnaire score: a meta-analysis. Rheumatol Int 2015;35:159-166.

58. Zhang L, Zhu J, Chen Y, Zhao J. Meta-analysis reveals a lack of association between a common catechol-O-methyltransferase (COMT) polymorphism val ${ }^{15}{ }^{8}$ met and fibromyalgia. Int J Clin Exp Pathol 2014;7:8489-8497.

59. Diatchenko L, Nackley AG, Slade GD, et al. Catechol-Omethyltransferase gene polymorphisms are associated with multiple pain-evoking stimuli. Pain 2006;125:216224.

6o. Jarcho JM, Mayer EA, Jiang ZK, Feier NA, London ED. Pain, affective symptoms, and cognitive deficits in patients with cerebral dopamine dysfunction. Pain 2012;153:744-754.

61. Wood PB. Role of central dopamine in pain and analgesia. Expert Rev Neurother 2008;8:781-797.

62. Malt EA, Olafsson S, Aakvaag A, Lund A, Ursin H. Altered dopamine D2 receptor function in fibromyalgia patients: a neuroendocrine study with buspirone in women with fibromyalgia compared to female population based controls. J Affect Disord 2003;75:77-82.

63. Wood PB, Schweinhardt P, Jaeger E, et al. Fibromyalgia patients show an abnormal dopamine response to pain. Eur J Neurosci 2007;25:3576-3582.

64. Holman AJ, Myers RR. A randomized, double-blind, placebo-controlled trial of pramipexole, a dopamine agonist, in patients with fibromyalgia receiving concomitant medications. Arthritis Rheum 2005:52:2495-2505.

65. Buskila D, Cohen H, Neumann L, Ebstein RP. An association between fibromyalgia and the dopamine $\mathrm{D}_{4}$ receptor exon III repeat polymorphism and relationship to novelty seeking personality traits. Mol Psychiatry 2004;9:730-731.

66. Park DJ, Kim SH, Nah SS, et al. Polymorphisms of the TRPV2 and TRPV3 genes associated with fibromyalgia in a Korean population. Rheumatology (Oxford) 2016;55:15181527.

67. Kim SK, Kim SH, Nah SS, et al. Association of guanosine triphosphate cyclohydrolase 1 gene polymorphisms with fibromyalgia syndrome in a Korean population. J Rheumatol 2013;40:316-322.

68. Thony B, Auerbach G, Blau N. Tetrahydrobiopterin biosynthesis, regeneration and functions. Biochem J 2000;347 Pt 1:1-16.

69. Tegeder I, Costigan M, Griffin RS, et al. GTP cyclohydrolase and tetrahydrobiopterin regulate pain sensitivity and persistence. Nat Med 2006;12:1269-1277.

70. Larson AA, Giovengo SL, Russell IJ, Michalek JE. Changes in the concentrations of amino acids in the cerebrospinal fluid that correlate with pain in patients with fibromyalgia: implications for nitric oxide pathways. Pain 2000;87:201-211.

71. Groth R, Aanonsen L. Spinal brain-derived neurotrophic factor (BDNF) produces hyperalgesia in normal mice while antisense directed against either BDNF or trkB, prevent inflammation-induced hyperalgesia. Pain 2002;100:171-181.

72. Kerr BJ, Bradbury EJ, Bennett DL, et al. Brain-derived neurotrophic factor modulates nociceptive sensory inputs and NMDA-evoked responses in the rat spinal cord. J Neurosci 1999;19:5138-5148.

73. Juhasz G, Dunham JS, McKie S, et al. The CREB1-BDNFNTRK2 pathway in depression: multiple gene-cognitionenvironment interactions. Biol Psychiatry 2011;69:762-771.

74. Murphy GM Jr, Sarginson JE, Ryan HS, O'Hara R, Schatzberg AF, Lazzeroni LC. BDNF and CREBı genetic variants interact to affect antidepressant treatment outcomes in geriatric depression. Pharmacogenet Genomics 2013;23:301-313.

75. Smith SB, Maixner DW, Fillingim RB, et al. Large candidate gene association study reveals genetic risk factors and therapeutic targets for fibromyalgia. Arthritis Rheum 2012;64:584-593.

76. Eglen RM, Hunter JC, Dray A. Ions in the fire: recent ionchannel research and approaches to pain therapy. Trends Pharmacol Sci 1999;20:337-342.

77. Dib-Hajj SD, Cummins TR, Black JA, Waxman SG. Sodium channels in normal and pathological pain. Annu Rev Neurosci 2010;33:325-347.

78. Vargas-Alarcon G, Alvarez-Leon E, Fragoso JM, et al. A SCN9A gene-encoded dorsal root ganglia sodium channel polymorphism associated with severe fibromyalgia. BMC Musculoskelet Disord 2012;13:23.

79. Vargas-Alarcon G, Fragoso JM, Cruz-Robles D, et al. Association of adrenergic receptor gene polymorphisms with different fibromyalgia syndrome domains. Arthritis Rheum 2009;60:2169-2173.

8o. Small KM, McGraw DW, Liggett SB. Pharmacology and 
physiology of human adrenergic receptor polymorphisms. Annu Rev Pharmacol Toxicol 2003;43:381-411.

81. Bjersing JL, Lundborg C, Bokarewa MI, Mannerkorpi K. Profile of cerebrospinal microRNAs in fibromyalgia. PLoS One 2013;8:e78762.
82. Bjersing JL, Bokarewa MI, Mannerkorpi K. Profile of circulating microRNAs in fibromyalgia and their relation to symptom severity: an exploratory study. Rheumatol Int 2015;35:635-642. 